NBER WORKING PAPER SERIES

INFORMING SPR POLICY THROUGH OIL FUTURES AND INVENTORY DYNAMICS

\author{
Richard G. Newell \\ Brian C. Prest \\ Working Paper 23974 \\ http://www.nber.org/papers/w23974 \\ NATIONAL BUREAU OF ECONOMIC RESEARCH \\ 1050 Massachusetts Avenue \\ Cambridge, MA 02138 \\ October 2017
}

We acknowledge funding from the National Science Foundation, the Department of Energy and NBER under grant 36269.00.04.00. We thank Christiane Baumeister and Lutz Kilian for helpful comments and data, as well as participants in an NBER conference on energy markets. This work is partially based on the OECD oil inventory data developed by the International Energy Agency, but the resulting work has been prepared by the authors and does not necessarily reflect the views of the International Energy Agency, nor the views of the National Bureau of Economic Research.

NBER working papers are circulated for discussion and comment purposes. They have not been peer-reviewed or been subject to the review by the NBER Board of Directors that accompanies official NBER publications.

(C) 2017 by Richard G. Newell and Brian C. Prest. All rights reserved. Short sections of text, not to exceed two paragraphs, may be quoted without explicit permission provided that full credit, including $\odot$ notice, is given to the source. 
Informing SPR Policy Through Oil Futures and Inventory Dynamics

Richard G. Newell and Brian C. Prest

NBER Working Paper No. 23974

October 2017

JEL No. H4,L78,Q41,Q48

\begin{abstract}
This paper examines how information on the time pattern of expected future prices for crude oil, based on the term structure of futures contracts, can be used in informing whether to draw down, or contribute to the Strategic Petroleum Reserve (SPR). Such price information provides insight on expected changes in the supply-demand balance in the market and can also facilitate costeffective transitions for SPR holdings. Backwardation in futures curves suggests that market participants expect shocks to be transitory, creating a stronger case for SPR releases. We use vector autoregression to analyze the relationship between the term structure of futures contracts, the management of private oil inventories, and other variables of interest. This relationship is used to estimate the magnitude of the impacts of SPR releases into the much larger global inventories system. Under the assumption that strategic releases can be modeled as surprise inventory additions, impulse response functions suggest that a strategic release of 10 million barrels would temporarily reduce spot prices by about $2 \%$ to $3 \%$ and mitigate backwardation by approximately 0.8 percentage points. Historical simulations suggest that past releases reduced spot prices by $15 \%$ to $20 \%$ and avoided about 5 percentage points of backwardation in futures curves, relative to a no-release counterfactual. This research can help policymakers determine when to release SPR reserves based on economic principles informed by market prices. It also provides an econometric model that can help inform the amount of SPR releases necessary to achieve given policy goals, such as reductions in prices or spreads.
\end{abstract}

\author{
Richard G. Newell \\ Duke University \\ Box 90328 \\ Durham, NC 27708 \\ and NBER \\ newell@rff.org \\ Brian C. Prest \\ Duke University, Box 90328 \\ Durham, NC 27708 \\ brian.prest@duke.edu
}




\title{
Informing SPR Policy Through Oil Futures and Inventory Dynamics
}

\author{
Richard G. Newell Brian C. Prest*
}

October 21, 2017

\begin{abstract}
This paper examines how information on the time pattern of expected future prices for crude oil, based on the term structure of futures contracts, can be used in informing whether to draw down, or contribute to the Strategic Petroleum Reserve (SPR). Such price information provides insight on expected changes in the supply-demand balance in the market and can also facilitate cost-effective transitions for SPR holdings. Backwardation in futures curves suggests that market participants expect shocks to be transitory, creating a stronger case for SPR releases. We use vector autoregression to analyze the relationship between the term structure of futures contracts, the management of private oil inventories, and other variables of interest. This relationship is used to estimate the magnitude of the impacts of SPR releases into the much larger global inventories system. Under the assumption that strategic releases can be modeled as surprise inventory additions, impulse response functions suggest that a strategic release of 10 million barrels would temporarily reduce spot prices by about $2 \%$ to $3 \%$ and mitigate backwardation by approximately 0.8 percentage points. Historical simulations suggest that past releases reduced spot prices by $15 \%$ to $20 \%$ and avoided about 5 percentage points of backwardation in futures curves, relative to a no-release counterfactual. This research can help policymakers determine when to release SPR reserves based on economic principles informed by market prices. It also provides an econometric model that can help inform the amount of SPR releases necessary to achieve given policy goals, such as reductions in prices or spreads.
\end{abstract}

\section{Introduction and Motivation}

Understanding the relationship between crude oil prices, inventories, and market expectations is crucial for understanding not only private market dynamics, but also the value and effectiveness of public inventories, particularly strategic reserves. If a significant portion of oil supply is disrupted, how would releasing oil from the U.S. Strategic Petroleum Reserve (SPR) and other international oil stock holdings affect oil prices? This depends on a number of factors, including whether the disruption is expected to intensify or attenuate, the

\footnotetext{
*Newell: Resources for the Future, 1616 P St NW, Washington, DC 20036, Duke University, Box 90328, Durham, NC 27708, and NBER (email: newell@rff.org). Prest: Duke University, Box 90328, Durham, NC 27708 (email: brian.prest@duke.edu). We acknowledge funding from the National Science Foundation, the Department of Energy and NBER under grant 36269.00.04.00. We thank Christiane Baumeister and Lutz Kilian for helpful comments and data, as well as participants in an NBER conference on energy markets. This work is partially based on the OECD oil inventory data developed by the International Energy Agency, (C) OECD/IEA 2016 but the resulting work has been prepared by the authors and does not necessarily reflect the views of the International Energy Agency.
} 
elasticity of oil demand and supply, and whether members of the Organization of the Petroleum Exporting Countries (OPEC) are likely to react to such a release. While these questions are important to guiding SPR drawdown policy, economic research on this topic is highly limited. This leaves policymakers with little economically-driven guidance. As a result, SPR release policy is typically informed by a combination of back-of-the-envelope estimates, qualitative market assessment, and simply "counting barrels", whereby policymakers release an amount of crude oil equal to the estimated size of the disruption.

This paper argues that the term structure of futures prices for crude oil can provide an indicator to policymakers on the severity of oil disruptions, and its relationship to inventories can help guide the magnitude of any response using strategic reserves. In particular, the spread between long- and short- dated crude futures prices reflects market expectations about the persistence of supply and demand shocks 11 In particular, SPR releases are more effective and appropriate in response to temporary supply shocks, and less so in the face of persistent shocks. The degree of contango (a positive spread between future and current prices) or backwardation (a negative spread) in crude oil markets provides market-based information about how persistent supply shocks are likely to be, with a higher degree of backwardation suggesting larger transitory shocks. While this differs from the common focus on the levels of spot prices, the economic theory of storage clearly implies that price spreads are the more important factor for stockpiling decisions (e.g., Working 1949. Brennan 1958; Fama and French 1987, 1988, Pindyck 2001) I $^{2}$ This suggests that policymakers can look to oil price spreads to gauge the expected persistence of a supply shock when considering SPR releases. It also suggests that better understanding of the dynamic relationships between spreads and private inventories can offer insights for when to release strategic reserves.

Aside from the question of whether to release oil reserves, policymakers also face the question of how much to release to achieve given policy goals. To consider this question, this paper also uses a vector auto-regression (VAR) model to empirically analyze the dynamic relationships between oil spot prices, price spreads, and privately-held commercial inventories. Once estimated, we use this model to estimate the impacts of a shock to private inventories (say, from an emergency infusion from public inventories) on oil prices, spreads, and other variables of interest. These estimated responses show substantial relationships between inventories and spreads, with a $1 \%$ crude oil inventory increase - equivalent to approximately 10 million barrels of crude oil - temporarily changing spreads by approximately 0.8 percentage points (i.e., a reduction in backwardation,

\footnotetext{
${ }^{1}$ Throughout this paper, the spread is defined as the difference between the 12-month and 1-month real crude oil futures prices: $p_{12}-p_{1}$, where prices are expressed in log terms to represent percentage differences. We also note the important caveat discussed in Baumeister and Kilian (2016b) that futures prices also reflect a risk premium in addition to expectations about future spot prices. We discuss this caveat more below and present a sensitivity analysis in the appendix.

${ }^{2}$ We use the term "spot" price informally as a shorthand to refer to the prompt-month oil future price, distinguishing it from longer-term futures prices.
} 
or increase in contango). This inventory shock reduces both spot and futures prices of crude oil. Spot prices temporarily fall by about $2 \%$ to $3 \%$, while 12 -month futures prices fall by a smaller amount, implied by the changing spread. Prices fall despite some potential offset by a decrease in OPEC supply, which is imprecisely estimated in our model.

We also use the model to simulate counterfactual release scenarios during relevant historical periods. These periods include times when oil was released from the SPR and times when such releases were considered but not executed. A simulation for 1991, during the Gulf War, suggests that the release contributed to the price decline and reduced backwardation that occurred in the months following the release and U.S. military actions. A simulation for 2011, during the Arab Spring, suggests that SPR release did indeed reduce backwardation in spreads, as well as prevented temporary steep rises in oil prices. A simulation for 2003, when oil futures entered steep backwardation but no SPR release occurred 3 suggests that a release during this period could have muted the strong backwardation and reduced prices temporarily. These simulations also provide guidance on the size of SPR releases needed to achieve given policy goals, such as reductions in oil prices or changes in price spreads.

\section{Background and Literature}

Governments have long held strategic petroleum reserves. In the wake of the 1973 OPEC oil embargo, the International Energy Agency (IEA) was established with a key purpose being the coordination of strategic reserves to respond to oil supply disruptions. The U.S. Strategic Petroleum Reserve was established shortly thereafter in 1975 for the same reason. Reserves have been released on three major occasions since then: during the 1991 Gulf War, during Hurricane Katrina in 2005, and during the 2011 Arab Spring There were also other times when SPR releases were considered but ultimately not used, such as in early 2003 when the Venezuelan oil strike and the Iraq War disrupted oil production: 5

Despite the importance of SPR release decisions, the economics literature provides little guidance for optimal policy. Instead, policymakers typically rely on expert judgment and back-of-the-envelope estimates of the impacts of releases on oil prices. A 2006 GAO report asked a group of experts about SPR policy, who generally suggested that strategic releases should be used to offset supply disruptions that the market

\footnotetext{
${ }^{3}$ This was amid the Venezuelan oil strike and run-up to the Iraq War, which together disrupted millions of barrels per day. Some experts argued that this case clearly called for SPR releases, but no releases were ultimately made.

${ }^{4}$ Reserves have also been released on other occasions, which mostly represent test sales, temporary loans, and sales for deficit-reduction.

${ }^{5}$ See Dobbs, Michael. "Oil Reserve Is 'First Line of Defense' for U.S." New York Times, 18 Feb. 2003.
} 
cannot make up on its own (e.g., through private inventory drawdowns or supply responses in other regions) 6 In other words, this is a policy of "counting barrels" that are disrupted on net, and releasing that amount of reserves. Indeed, in its recent strategic assessment and benefit analysis for the SPR, the Department of Energy assumed exactly this decision rule 7

This policy of counting barrels is inadequate because it does not incorporate market expectations about the expected persistence of supply disruptions. Further, it embodies the outdated notion that the SPR is for addressing physical shortages. In a globally integrated market, the SPR primarily addresses the economic impacts of price shocks - both its macroeconomic and distributional effects. If the goal of the SPR then is to dampen or eliminate price shocks associated with supply disruptions, how do policy-makers decide whether a particular situation warrants release and how large it should be, given that simply counting barrels is insufficient? There is no literature on this issue that we are aware of.

The initial literature on SPR management dates back to the late 1970s and early 1980s-the years following the oil shocks of the Arab oil embargo, the Iranian Revolution, and the establishment of the reserve. These studies include Teisberg (1981) and Chao and Manne (1983), which use dynamic programming to model optimal SPR filling and release policies. One result of those studies is that releasing reserves is more desirable when the disruption is likely to be temporary (rather than persistent).

But they did not explore how to determine the probabilities of persistence in practice; rather, the authors assumed constant transition probabilities. One reason for this is that literature did not have access to the information about expectations provided by oil futures markets, simply because the studies pre-dated the existence of those markets. Hubbard and Weiner (1983, 1985, 1986) use economic models to study the impacts of SPR releases, but they also pre-dated the establishment of long-dated futures contracts. Short-run oil futures markets were established in 1983, and liquid markets for long-dated contracts did not arise until the late 1980s. In light of this, Devarajan and Hubbard (1982) was ahead of its time in arguing that the SPR should sell futures contracts to accelerate the impact of strategic releases. The establishment of long-dated contracts creates more information about expected future spot prices, to which the existing dated literature did not have access.

Literature conceptualizing the relationship between inventories and price spreads dates back to Working (1949); Brennan (1958), was supported empirically for many commodities in Fama and French (1987, 1988)

\footnotetext{
${ }^{6}$ See GAO, "Strategic Petroleum Reserve", 2005.

${ }^{7}$ See Department of Energy, "Long-Term Strategic Review (LTSR) of the U.S. Strategic Petroleum Reserve (SPR) Report to Congress", 2016. In particular, the benefit analysis assumed that net supply disruptions would be offset one-for-one by coordinated IEA releases.
} 
(although they did not consider oil) and is summarized by Pindyck (2001). Intuitively, these studies present a now standard no-arbitrage result from finance that in equilibrium the futures price spread (the benefit from holding inventories) must equal the net cost of storage and lost interest accounting for the risk premium (together representing the cost of holding inventories). While inventory activity upholds this equilibrium, inventories do not appear explicitly in this result or as a function of spreads. We directly estimate this relationship.

There is a recent empirical literature on oil inventories, including Kilian and Lee (2014) and Baumeister and Kilian (2016a), and we follow those studies in using vector autoregression (VAR) to model oil market dynamics methods. However, those studies estimate the relationship between inventories and oil price levels, not spreads. Kilian and Murphy (2014) considered spreads as an auxiliary analysis, but they were not used in their main model or structural analysis. None of those studies are focused on informing SPR policy. In addition, a working paper by Stevens (2014) considers the impacts of SPR purchases and releases (both emergency and routine) on crude oil prices (but not spreads), finding little impact except in times of high market uncertainty. That study does not incorporate price spreads into its analysis, which is the focus of this paper. That study does consider the effect of SPR releases on (a subset of) U.S. crude inventories, but only as an auxiliary analysis 8

This study also contributes to a larger literature that uses time series methods to study oil market dynamics. These include Kilian (2008, 2009); Hamilton (2009); Kilian (2016, 2017a b), which generally consider dynamics between oil prices and supply and demand factors. None of those studies, however, focuses on the relationship of inventories and price spreads. The only study of which we are aware estimating a relationship between crude oil inventories and price spreads is Scheitrum, Carter, and Jaffe (2015), which considers whether strategic releases themselves (or expectations thereof) affect the behavior of private inventories. The spread-inventory relationship is not the relationship of interest in that study. In addition, the study considers only the effects of spreads on inventories, and not the reverse relationship (inventories affecting spreads) that we also estimate.

One other study that is relevant for this research is Baumeister and Kilian (2016b), which distinguishes between oil price futures and expected future oil prices. While often conflated, these two differ according to the risk premium. Conceptually, this matters when using futures prices as a proxy for expected prices in the

\footnotetext{
${ }^{8}$ Specifically, it considers the impacts on oil inventories located in U.S. PADDs 2 and 3 (as opposed to our more comprehensive global measure) as a side analysis. It ultimately does not include private inventories in its main analysis. That study also differs from ours in that it uses routine SPR purchases and sales for identification of the impacts of releases on oil price levels, whereas we consider variation in private inventories to identify impacts on spreads (as well as prices and other variables).
} 
future and hence the expected persistence of supply shocks. Econometrically, this matters when computing the price "spread" against the prompt-month oil price. To explore the impact of this distinction on our results, we estimate our models using both methods. We first estimate the model with the spread computed as the difference between long-dated and prompt-month futures prices. We then run sensitivities by estimating the model with spreads computed as the difference between the expected future spot prices (estimated by Baumeister and Kilian 2016b) and prompt-month futures prices. Our key results are robust to using either method.

In summary, there is little to no recent economic literature considering the relationship between oil inventories and price spreads or guiding SPR policy. This paper contributes significantly in these areas, and provides important guidance to future SPR release policy.

\section{Methods and Data}

In this section, we overview the methods and data we use in our estimation and simulations. First, we provide an overview of the vector autoregression model, the computation of cumulative impulse response functions, and how we run counterfactual simulations of SPR release scenarios. This section also includes a summary of the data used and its sources.

\subsection{Methods}

\subsubsection{VAR Model}

We estimate a vector autoregression (VAR) with $K=5$ variables: OECD petroleum consumption, OECD commercial crude inventories, OPEC crude oil production, crude oil prices, and price spreads. With one exception (spreads), variables are expressed in log-changes, implying percentage changes after taking first differences. We take first differences because the series are generally non-stationary in levels, but are stationary in differences. We include the spread in levels, rather than first differences, because futures and spot prices are cointegrated (although the results are very similar if we estimate with the spread in first differences).

It is natural to include crude inventories, prices, and spreads based on the discussion above. We also include OECD petroleum consumption as a measure of oil demand. We control for oil demand shocks to disentangle inventory shocks that are driven by supply-driven versus demand-driven factors. OPEC 
crude production is included because OPEC supply responses are a potential moderating factor in inventory dynamics and SPR releases 9

As our measure of crude oil prices, we use monthly changes in West Texas Intermediate (WTI) prices for years prior to 2010, switching to changes in Brent crude oil prices in January 2010. We make this adjustment for several reasons. First, while the Brent price is the most common benchmark in recent years, WTI contracts were the benchmark in earlier decades. The Brent futures market was significantly less liquid than WTI in the 1980s and 1990s, making the latter a better metric historically. Second, as documented by Kilian (2016), the tight oil boom in the United States de-linked WTI and Brent prices beginning in 2010 ${ }^{10}$ As a result of this disconnect in recent years, backwardation in WTI prices have not always coincided with backwardation in Brent prices, the latter of which is now the common benchmark considered as an indicator for the global oil market. For this reason, we use Brent prices post-2010. For the remainder of this paper, we use the term "crude oil" prices, referring to this combined time series.

Our VAR specification is

$$
\mathbf{y}_{t}=\mathbf{A}_{0}+\sum_{\ell=1}^{24} \mathbf{A}_{\ell} \mathbf{y}_{t-\ell}+\varepsilon_{t}
$$

where

$$
\mathbf{y}_{t}=\left(\begin{array}{c}
\Delta \text { OECD Petroleum Consumption }_{t} \\
\Delta \text { OECD Commercial Crude Oil Inventories }_{t} \\
\Delta \text { OPEC Crude Oil Production } \\
t \\
\Delta \text { Real Crude Oil Prompt-Month Price } \\
t \\
\text { Crude Oil 12-Month Spread }
\end{array}\right.
$$

and variables are measured in logs. Spreads represent the log difference between the 12-month and promptmonth real crude futures price, so it can be interpreted as a percentage point. In interpreting our results, we implicitly treat the 12-month futures price as a market-based expectation of future spot prices. However, as documented by Baumeister and Kilian (2016b), futures prices differ from expected spot prices due to a

\footnotetext{
${ }^{9}$ Our key results are qualitatively similar if we were to exclude OPEC production (or replace it with world crude oil production). We include it nonetheless because it is an important factor affecting oil markets. Further, including it allows us to simulate its dynamics as well, including OPEC supply responses to inventory shocks.

${ }^{10}$ Prices and spreads were similar for both Brent and WTI in both December 2009 and January 2010, making this a reasonable breakpoint.
} 
time-varying risk premium. As a sensitivity, we also estimated the VAR using a time series of 12-month-ahead expected spot prices generously provided by Baumeister and Kilian (2016b) to construct our spread variable. The estimates are very similar and can be found in the appendix 11 We nonetheless present the results using actual futures prices because that is the information that would be available to a policymaker during an emergency oil supply disruption.

We also include twelve monthly dummy variables in the estimation, but do not include them in the equations below for notational convenience. The sample period is December 1988 through June 2016, monthly. We use 24 lags (2 years), following Hamilton and Herrera (2004); Kilian (2009); Kilian and Lee (2014); Kilian and Murphy (2014), and Kilian and Lütkepohl (2017), which stress the need for including many lags to account for slow-moving dynamics in oil markets.

\subsubsection{Cumulative Impulse Response Functions}

In what follows, we overview impulse response functions (IRFs) for those less familiar with them. Readers comfortable with IRFs may wish to skip to the next subsection, 3.1.3. We present the results through cumulative orthogonalized impulse response functions. These represent how each of the variables change over time $(t+s)$ in response to a one-unit orthogonalized shock to one of the variables $(j)$ at time $t$. The formula for IRFs can be derived analytically through the moving average representation of the VAR:

$$
\mathbf{y}_{t}=\Phi_{0} \varepsilon_{t}+\Phi_{1} \varepsilon_{t-1}+\Phi_{2} \varepsilon_{t-2}+\ldots
$$

where $\Phi_{0}=I_{K}, \Phi_{1}=\mathbf{A}_{1}$ and the subsequent $\Phi_{s}$ matrices are defined recursively as

$$
\Phi_{s}=\sum_{\ell=1}^{s} \Phi_{s-\ell} \mathbf{A}_{\ell}
$$

The $(i, j)$ element of $\Phi_{s}$ gives the expected response of variable $i, s$ periods after a unit shock to only variable $j$. Of course, the shocks to the five variables are likely to be correlated, meaning a shock to variable $j$ is likely to be accompanied by shocks to other variables. For example, expectedly large inventory shocks are likely to put downward pressure on oil prices immediately, and indeed we find a negative correlation between

\footnotetext{
${ }^{11}$ The impulse response functions were qualitatively unchanged when using the Baumeister and Kilian (2016b) data to construct the spreads. The only significant impacts were on the IRFs involving spreads themselves. The responses of spreads to all impulses are somewhat larger when using the Baumeister and Kilian (2016b) data, and the response of prices and OPEC production to spread shocks also increased somewhat (although with large standard errors). These changes generally do not affect our relationships of interest, which is the effect of inventory shocks. Further, caution should be taken in comparing these across models, since they represent conceptually different spread variables; one measure includes the risk premium and the other does not.
} 
these residuals. The orthogonalization process accounts for the correlation in these shocks, de-correlating the $\varepsilon_{t}$ vector by multiplying it by the Cholesky decomposition of the residual covariance matrix, $L$ (so $\left.L L^{\prime}=\Sigma_{\varepsilon \varepsilon^{\prime}}=\operatorname{cov}\left(\varepsilon_{t}, \varepsilon_{t}^{\prime}\right)\right)$. This results in uncorrelated shocks, denoted $\boldsymbol{u}_{t}=L \boldsymbol{\varepsilon}_{t}$. The orthogonalized IRF $(\mathrm{OIRF})$ is

$$
\Psi_{s}=\Phi_{s} L
$$

representing the expected responses of the variables to these orthogonalized shocks ${ }^{12}$ Intuitively, this accounts for the immediate relationships between the variables through the correlation of the residuals.

As is well known, the ordering of the variables matters in the orthogonalization because the Cholesky decomposition is lower triangular. Variables placed earlier in the ordering are effectively assumed to be "slower moving" than variables placed later ${ }^{13}$ For example, OECD petroleum consumption, being placed first in equation 2 , is not allowed to respond within-period to any shocks in other variables, only responding with a lag through the lag structure in equation 1. OPEC production, being placed in the middle, can immediately respond to shocks to consumption and crude inventories, but it only responds to shocks to crude prices and spreads through the lag structure in equation 1. Crude prices and spreads are placed at the end, allowing them to response to shocks in all preceding variables ${ }^{14}$ We argue that this ordering is reasonable. Prices and spreads can and do change instantly in response to news, justifying their placement at the end. OPEC production (placed third) is clearly slower moving than prices, and OPEC's historic status as swing producer suggests that it can adjust more quickly than commercial inventories (placed second), which requires changes to flow supply or demand and the movement of physical barrels. Lastly, petroleum consumption is a very slow moving series, justifying its placement first in the VAR.

Because our variables are in monthly changes (with the exception of the spread), $\Psi_{s}$ represents the impacts of a shock on monthly changes in variables after $s$ periods. Since we are interested primarily in the levels of variables of interest (e.g., oil prices) and not their monthly changes, we present cumulative impulse response functions $\left(\sum_{\ell=1}^{s} \Psi_{\ell}\right)$ for all variables in first differences. This accumulates the effects on monthly changes in the variables to show the impact on their (log) levels over time. For spreads, we report standard impulse response functions because that variable is already in levels. We construct $95 \%$ confidence intervals through residual-resampling bootstrap.

\footnotetext{
${ }^{12}$ While the multiplication by $L$ itself scales the shocks to one standard deviation shocks (instead of one-unit), we rescale these responses by the inverse of the standard deviations to once again represent unit changes.

${ }^{13}$ The alternative would be to use non-orthogonalized shocks. This would implicitly make the stronger assumption that shocks are contemporaneously unrelated, contrary to the observed correlations.

${ }^{14}$ The relative ordering of spreads and prices prevents prompt-month prices from immediately responding to spread shocks, implicitly treating spread shocks as shocks to futures prices alone. Interchanging the order of these two variables has zero effect on the key OIRF of interest, which is the response to inventory shocks.
} 


\subsubsection{Simulations}

In addition to computing impulse responses, we conduct counterfactual historical simulations to estimate how SPR releases would affect crude oil prices and spreads over time. We model a strategic release as an unexpected inflow to (i.e., increase in) commercial crude inventories.

For each simulation, we first choose a month $(\tau)$ and size $\left(r_{\tau}\right)$ for incremental SPR release we are simulating 15 We compute a new "counterfactual" shock that month, $\varepsilon_{\tau}^{c f}$, by adjusting the observed residual that month $\varepsilon_{\tau}$, according to an orthogonalized inventory shock of $r_{\tau}$ :

$$
\varepsilon_{\tau}^{c f} \equiv \varepsilon_{\tau}+\frac{1}{L_{(2,2)}} L\left(\begin{array}{c}
0 \\
r_{\tau} \\
0 \\
0 \\
0
\end{array}\right)
$$

The division by $L_{(2,2)}$ (which is approximately the standard deviation of the inventory residual) is required because the pre-multiplication by $L$ scales the magnitude of shock into one of $r_{\tau}$ standard deviations. This conversion ensures that the inventory residual, $\varepsilon_{2, \tau}$, changes by precisely the assumed SPR release size, $r_{\tau}$. The orthogonalization captures the immediate impacts that inventory releases may have on oil prices and spreads, based on the correlation of the VAR residuals ${ }^{16}$

All other residuals are left unchanged: $\varepsilon_{t}^{c f} \equiv \varepsilon_{t}$ for $t \neq \tau$.

With this one residual changed, counterfactual values of $\mathbf{y}_{t}^{c f}$ can be recursively simulated as

$$
\mathbf{y}_{t}^{c f} \equiv \mathbf{A}_{0}+\sum_{\ell=1}^{24} \mathbf{A}_{\ell} \mathbf{y}_{t-\ell}^{c f}+\varepsilon_{t}^{c f}
$$

where $\mathbf{y}_{t}^{c f}=\mathbf{y}_{t}$ for $t<\tau$ and the monthly dummies are suppressed for notational convenience. While $\mathbf{y}_{t}^{c f}$ are in log-differences, we aggregate up to levels when presenting the simulation results (e.g., barrels for inventories or dollars per barrel for oil prices) to make them easier for the reader to interpret. We compute simulated confidence intervals using the same bootstrap method commonly used to construct such intervals for IRFs.

\footnotetext{
${ }^{15}$ In simulations where we are simulating a counterfactual of no SPR release, $r_{\tau}$ is set to equal to the negative of the actual observed historical release. This effectively "subtracts" the observed historical release.

${ }^{16}$ For example, a 1 percent shock in inventories is estimated to be associated with an immediate reduction in spot prices of approximately 0.9 percent and an increase in spreads of approximately 0.4 percent. That is, with $r_{\tau}=0.01$, the last term in equation $\sqrt{3}$ is approximately $(0,0.01,-0.0003,-0.009,0.004)^{\prime}$ (with the final two elements representing percentage changes in oil prices and spreads, respectively).
} 


\subsection{Data}

We use data from three sources. Oil prices are obtained from Bloomberg L.P ${ }^{17}$ Daily prices are averaged to the monthly level and converted to real 2014 dollars using the CPI All Urban Consumer (All Items) index. Spreads are computed as the log of real 12-month futures prices minus the log of real prompt-month prices. This log difference thus approximately represents spreads in percentages. It also creates an exact linear relationship between log prices and spreads, which aids in interpreting the results.

The OECD commercial crude oil inventory series is from the International Energy Agency (IEA) 18 It corresponds to the crude stocks reported in their monthly Oil Market Reports, typically shown in their table titled "OECD Industry Stocks and Quarterly Stock Changes" 19 The OECD petroleum consumption and OPEC crude oil production series are from the U.S. Energy Information Administration (EIA) ${ }^{20}$ All five time series are shown in Figure 1. That figure shows the series in levels, but as previously mentioned we use their log-changes in the estimation.

\section{Results}

\subsection{Cumulative Impulse Response Functions}

While there are many impulse-response relationships implied by our VAR estimation, the primary relationship of interest is the effect of a shock to inventories. This is because we wish to model the effect of SPR releases, which amounts to making additional strategic inventories available to the market. To this end, we consider the responses of each variable to a $1 \%$ impulse to commercial crude inventories, shown in Figure 2 along with $95 \%$ confidence intervals ${ }^{21}$ When the responses are statistically significant, their direction and size generally comport with economic theory and intuition. As seen in the top middle chart (the effect of the inventory shock on inventories themselves), the inventories remain elevated after the shock, although much of the surplus is drawn down within two months ${ }^{22}$ The impacts on crude oil prices and spreads are shown in

\footnotetext{
${ }^{17}$ We use WTI and Brent prices, which use the CL1 Comdty and CL12 Comdty tickers (for WTI) and CO1 and CO12 Comdty tickers (for Brent), where the 1 and 12 in the tickers represent the prompt-month and 12-month contracts respectively.

${ }^{18}$ IEA data is from the Monthly Oil Survey, (c) OECD/IEA 2016, www.iea.org/statistics License: www.iea.org/t\&c; as modified by the authors.

${ }^{19}$ See https://www.iea.org/oilmarketreport/reports/ for an archive of these reports. Our data does not precisely match the data in the archived reports because the series is continually updated by IEA. We obtained the series from IEA in August 2016, and it is complete through June 2016.

${ }^{20}$ These series are publicly available at https://www.eia.gov/totalenergy/data/browser/index.php?tbl=T11.02\#/?f=M\& charted=10 and https://www.eia.gov/totalenergy/data/monthly/\#international respectively.

${ }^{21} \mathrm{~A} 1 \%$ inventory shock is on the order of 10 million barrels of crude oil, since private inventories are on the order of 1 billion barrels (see Figure 1]. Because of the linearity of the VAR model, all effects scale linearly with the inventory shock. For example, an inventory shock of $2 \%$ would be estimated to produce responses that are exactly twice as large as those from a $1 \%$ shock.

${ }^{22}$ This is consistent with Hubbard and Weiner (1986), which finds that private inventories do not fully absorb strategic releases.
} 

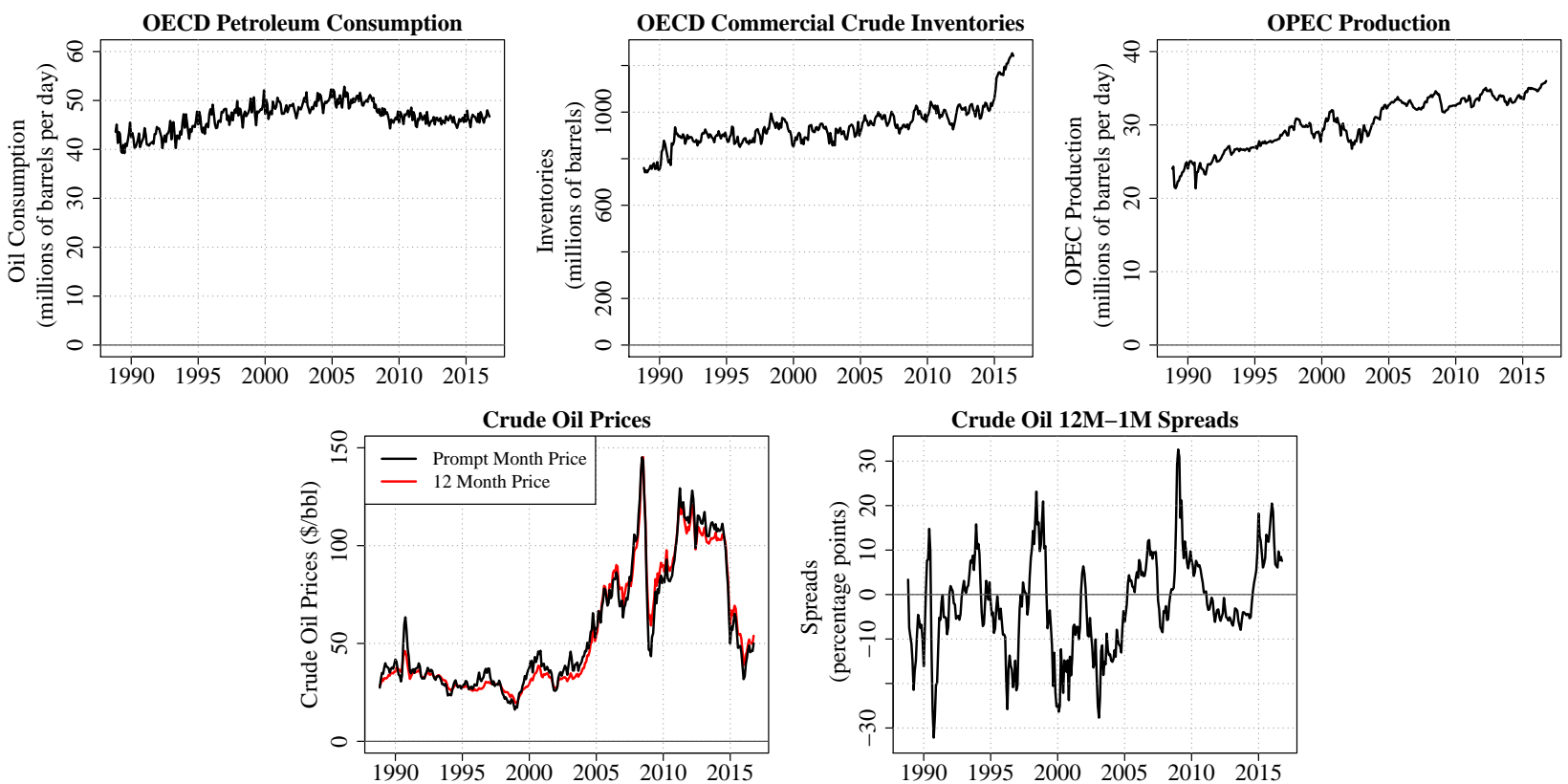

Figure 1: Time Series of OECD Petroleum Consumption, OECD Commercial Crude Inventories, OPEC Crude Oil Production, Crude Oil Prices, and Crude Price Spreads

the bottom two charts of Figure 2. We see an immediate reduction in spot prices which grows in magnitude to $-2 \%$ to $-3 \%$ over several months, before beginning to revert towards zero after approximately one year (in both point estimate and statistical significance). At the same time, spreads temporarily change by about 0.8 percentage points as this spot price reduction is accompanied by a smaller reduction in futures prices ${ }^{23}$ Price spreads revert back toward baseline conditions within about one year. Under the assumption that releases of strategic reserves can be modeled as surprise inventory builds, this suggests that SPR releases can reduce prices and mitigate backwardation, relative to a counterfactual of no release.

The response of OPEC production is slightly negative, implying OPEC reducing output somewhat in response to inventory builds, although the estimate is generally statistically insignificant ${ }^{24}$ The response of OECD petroleum consumption is also small and statistically insignificant 25

\footnotetext{
${ }^{23}$ While the 12-month futures price does not explicitly appear in the VAR, it appears implicitly through its additive relationship between spot prices and spreads. Namely, since spreads are computed as the log-difference between future and spot prices $($ Spread $=\ln ($ Future $)-\ln ($ Spot $))$, the effect on futures prices is the sum of the effect on spot prices and spreads $\left(\ln (\right.$ Future $)=\ln ($ Spot $)+$ Spread, which implies $\left.\frac{\partial \ln (\text { Future })}{\partial u_{j, t}}=\frac{\partial \ln (\text { Spot })}{\partial u_{j, t}}+\frac{\partial \text { Spread }}{\partial u_{j, t}}\right)$. So, for example, after about 12 months, a $-2.3 \%$ change in spot prices accompanied by a $0.4 \%$ change in spreads implies a $-1.9 \%$ change in futures prices $(=-2.3 \%+0.4 \%)$.

${ }^{24}$ Excluding OPEC production from the model has little effect on the responses of the remaining variables.

${ }^{25}$ If we exclude OECD petroleum consumption from the estimation, the price and spread responses to an inventory shock are larger and more persistent, suggesting that its inclusion is controlling for demand-driven inventory builds, as desired. As suggested by a commenter on an early version of this paper, excluding demand from the estimation would threaten to attribute the effects of (relatively persistent) demand shocks to an effect of inventories, thereby overstating of the strength and persistence of inventory shocks that are driven by transitory factors such as supply shocks. The fact that excluding petroleum demand from the estimation results in larger and more persistent estimates suggests that its inclusion is acts as a valuable control for our purposes.
} 

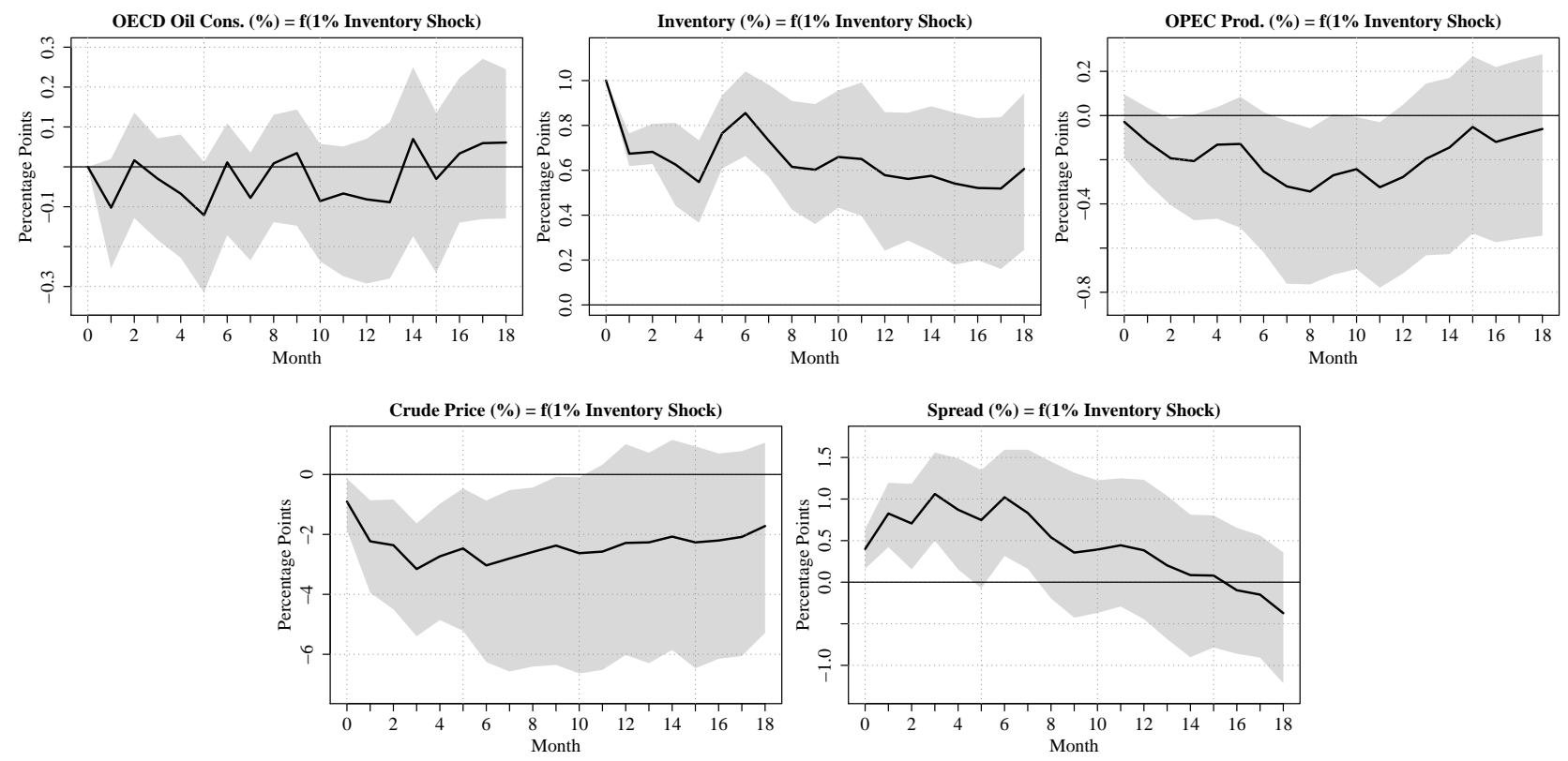

Figure 2: Cumulative Impulse Responses from a 1 Percentage Point Shock to Inventories

Notes: Shaded areas represent 95\% confidence intervals computed through 100 bootstrap iterations.

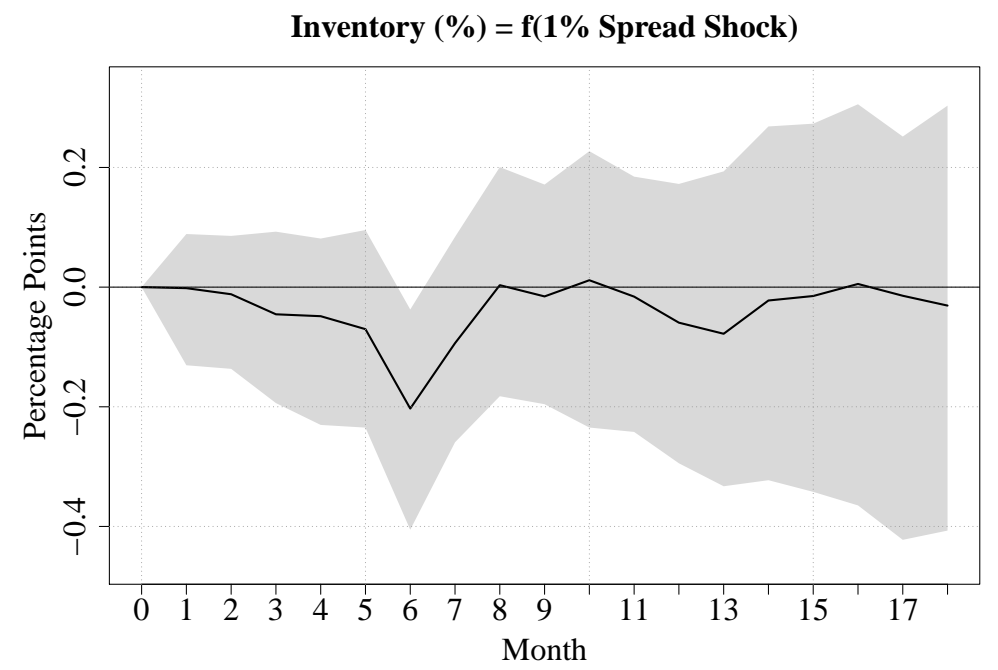

Figure 3: Cumulative Inventory Response from a 1 Percentage Point Shock to Spreads

Notes: Shaded areas represent 95\% confidence intervals computed through 100 bootstrap iterations. 
We explored the other impulse response functions, which estimate the effects of impulses in each of the other variables (e.g., petroleum consumption, OPEC production, and spreads) on each other. These OIRFs can be found in the appendix. When the responses are statistically significant, their direction and size generally comport with economic theory and intuition. Of interest, we find that the effect of spread shocks on inventories is small and statistically insignificant, as shown in Figure 3 . This suggests that the causal relationship runs from inventories to spreads, not vice versa ${ }^{26}$ This is intuitive, since market prices can and do change instantly in response to news about inventories, whereas inventory builds require adjustments to flow supply and/or demand and the movement of physical barrels.

\subsection{Simulations}

We use our estimated VAR to conduct counterfactual simulations to illustrate the estimated impacts of actual and hypothetical strategic releases during three historical periods: the 1991 Gulf War, the 2003 Venezuelan oil strike and Iraq War, and the 2011 Arab Spring. The first and third scenarios involve historical strategic releases (1991 Iraq War, 2011 Arab Spring), so we simulate a no-release counterfactual. In the second scenario, we consider the impact of an SPR release at a time when it was considered but not executed, so we simulate a counterfactual release.

\subsubsection{Simulation 1: 1991 Gulf War}

The first simulation is in January 1991, when the run-up to the Gulf War caused prices to double and enter steep backwardation amid uncertainty about Iraq's oil supply. In January 1991, the United States and IEA jointly made available approximately 60 million barrels of oil ${ }^{27}$ Oil prices declined sharply after the release, but economists note that it is difficult to disentangle the contributions of the release itself and the relatively swift resolution to the conflict. The latter is unmodelled in our approach and hence appears in the residual. As explained above, our simulation retains the residual but estimates the effect of the change in crude oil inventories by implementing an additional inventory shock (here, by subtracting from inventories the 60 million barrels that were actually made available by IEA). This simulation helps to disentangle these two effects.

\footnotetext{
${ }^{26}$ This finding is robust to the ordering of the variables in the VAR, implying it is not simply the result of the orthogonalization. ${ }^{27}$ See http://articles.latimes.com/1991-01-18/business/fi-102_1_oil-prices.
} 

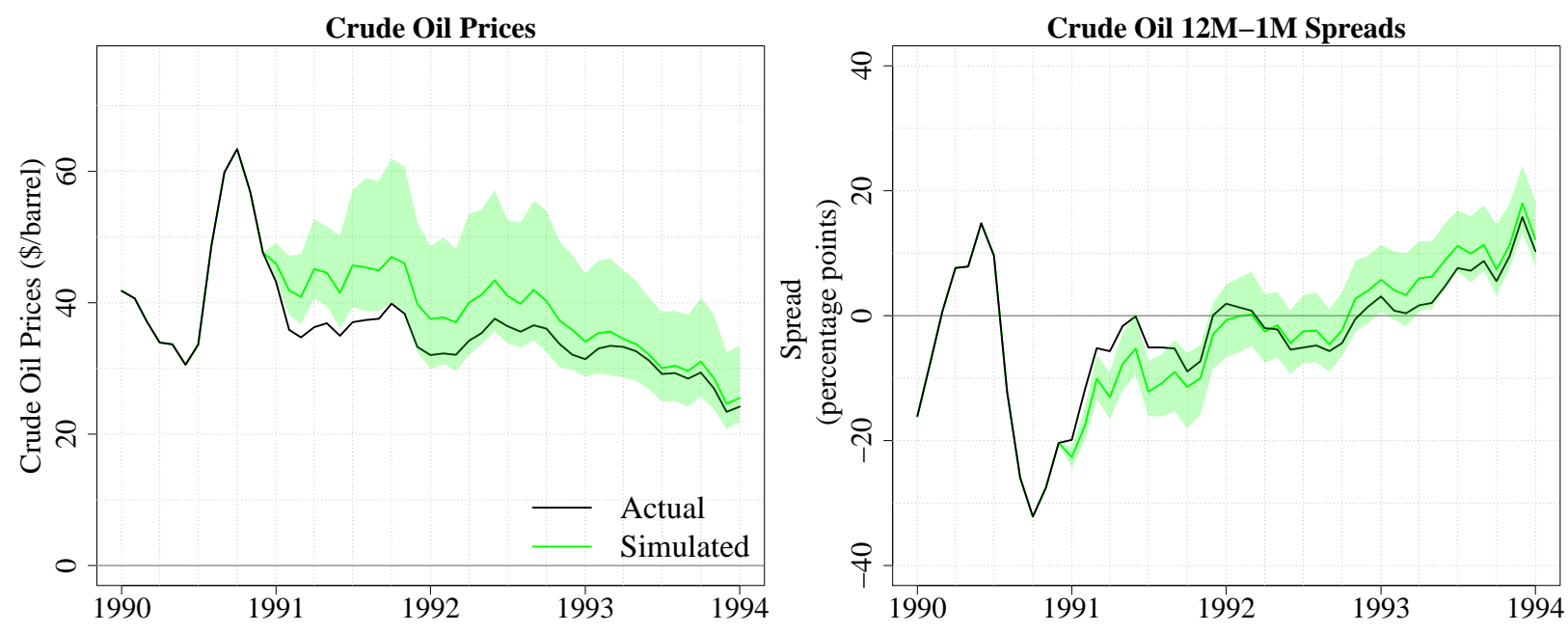

Figure 4: Simulation without Strategic Release in January 1991

Notes: The shaded areas represent bootstrapped $95 \%$ confidence intervals. The assumed inventory shock is -60 million barrels of crude oil $(\approx-6.9 \%$ of inventories then), approximately equal to the amount total IEA release at the time.

Figure 5 shows oil prices and spreads, both actual values (in black) and simulated values without the release (in green). The shaded areas represent bootstrapped $95 \%$ confidence intervals for the simulation 28 The simulation suggests that, absent the IEA release, oil prices would have remained somewhat elevated, although not at the $\$ 60$ peak level. Prices would have only declined to approximately $\$ 45$, rather than the actual levels of about $\$ 37$, for an impact of about $\$ 8$ (or $20 \%$ ). The reduction in backwardation would have been somewhat smaller, with spreads remaining at about $-10 \%$ compared to the observed values of about $-5 \%$, for an impact of about +5 percentage points attributable to the release.

For both prices and spreads, the simulated impact of the release is only statistically significant for a short period of time, and generally insignificant after about 9 to 12 months, with the point estimates of the simulated values eventually reverting to actual levels, implying no strong long-run effect ${ }^{29}$ The simulation suggests that the release led to an economically significant, short-run reduction in prices and backwardation.

\subsubsection{Simulation 2: 2003 Iraq War}

The next simulation is for spring 2003, when there were two significant supply disruptions in a short period of time: the Venezuelan oil strike and the Iraq War. The Venezuelan oil strike began in late 2002, disrupting

\footnotetext{
${ }^{28}$ These intervals are confidence intervals based on uncertainty of parameter estimates, not to be confused with prediction intervals, which would additionally simulate new draws for the error terms.

${ }^{29}$ This temporary nature of the effect is not an inevitable consequence of the VAR model or the assumed number of lags (24). First, as is clear from the moving average representation of VARs, the model allows effects to persist for much longer. Second, these responses represent accumulated effects on monthly changes. While the effect on monthly changes asymptotes to zero in the long run, the accumulation of these changes need not do so.
} 

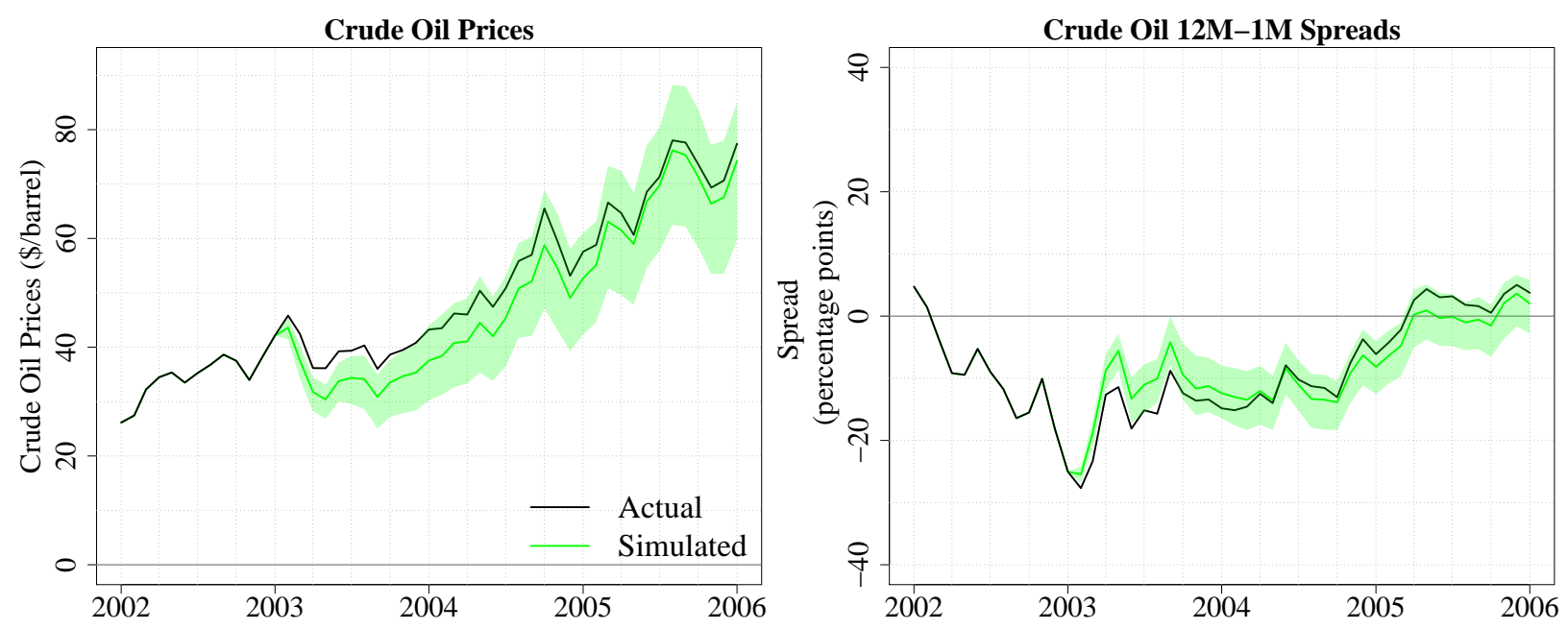

Figure 5: Simulation with Strategic Release in February 2003

Notes: The shaded areas represent bootstrapped $95 \%$ confidence intervals. The assumed inventory shock is +48 million barrels of crude oil ( $\approx 5.5 \%$ of inventories then), equal to the net disruption in production of 0.8 million barrels per day for a period of 2 months.

over 2 million barrels per day in supply (Nov-2002 to Jan-2003). This disruption was in the process of being resolved in early 2003, when the invasion of Iraq disrupted 1.3 million barrels per day (Mar-03 to Apr-03). Some of this disruption was offset by a 0.5 million barrel per day increase in production from other OPEC nations, so the net disruption from OPEC members was 0.8 million barrels per day. Spot crude prices rose sharply, sending the futures market into deep backwardation in excess of 20\% (during Jan-03 to Mar-03). We model a strategic release of 48 million barrels, equal to two months of disrupted supply (0.8 million barrels per day for 60 days). Other recent strategic releases were of similar order of magnitude (typically about 60 million barrels), so this figure is a reasonable approximation of what an actual release might have been. We simulate the release occurring in February 2003, which was the month of steepest backwardation.

As seen in Figure 4 the simulated release of crude oil temporarily results in a spot price reduction of about $\$ 6$, or approximately $15 \%$. Simulated spreads show temporarily reduced backwardation, falling to about $-10 \%$ instead of $-15 \%$, for an impact of about +5 percentage points attributable to the release. As before, these effects are only statistically significant for a period of a few months, and the estimated effect virtually disappears after a year or more. Simulated spreads eventually recover to the actual levels, and the counterfactual prices rise toward actual prices.

In summary, this simulation suggests that strategic releases could have mitigated the short-term price increases and backwardation brought on by the 2003 Iraq War and Venezuelan oil strike. 

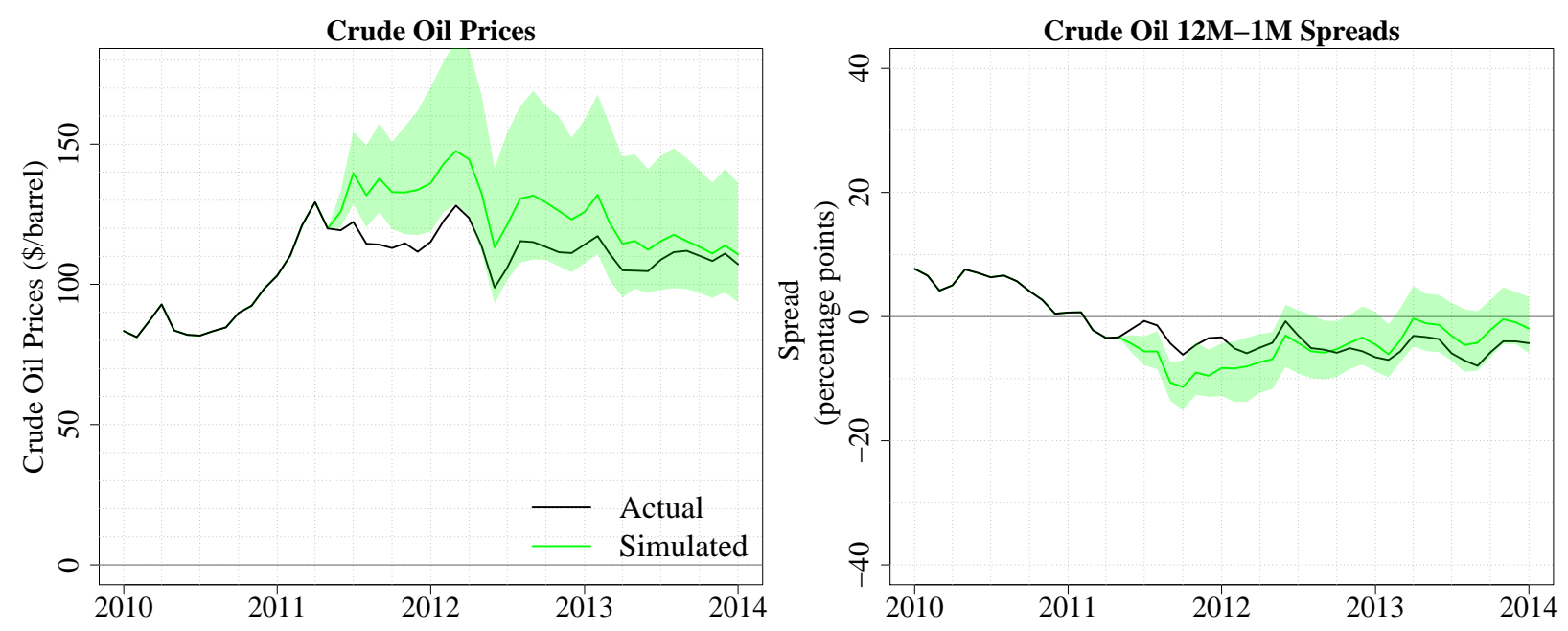

Figure 6: Simulation without Strategic Release in June 2011

Notes: The shaded areas represent bootstrapped $95 \%$ confidence intervals. The assumed inventory shock is -60 million barrels $(\approx-6.4 \%$ of inventories then $)$, equal in magnitude to the total IEA release that year.

\subsubsection{Simulation 3: 2011 Arab Spring}

Our final simulation considers the strategic release of reserves during the 2011 Arab Spring, which disrupted oil supply in Libya and other countries. In June 2011, IEA member countries announced a release of 60 million barrels of oil, which were delivered by August 2011. As in the first simulation, we simulate a scenario without this release by introducing a negative inventory shock of 60 million barrels in June 2011. The results are in Figure 6. The figure suggests that the release prevented a temporary increase in prices and backwardation. With the releases, prices remained relatively stable around $\$ 110$ with a spread of about $-5 \%$, compared to the counterfactual case where in the short term prices rise to about $\$ 135$ per barrel and spreads moved into backwardation of about $-10 \%$. This suggests that the 2011 strategic releases may have reduced price increases by about 20\% ( $\$ 110$ versus $\$ 135)$ and backwardation by about 5 percentage points (-5\% versus $-10 \%)$, consistent with the previous simulations.

\section{Caveats}

The results indicate an economically and statistically significant effect of inventory changes on spot prices and price spreads. Based on these estimated relationships, the above simulations also suggest that strategic releases can effectively moderate price increases and stabilize futures spreads in times of market dislocation. There are, however, important caveats. First, we simulate strategic releases as a surprise shock to private 
inventories. This implicitly assumes that market actors respond to surprise public releases in the same way that they would respond to surprise increases in private inventories. We have controlled for demand shocks, so the estimated response to an inventory shock is based on supply-driven factors. Nonetheless, market actors may interpret supply-driven inventory shocks differently (say, because they believe public releases signal future government policy), and hence they may react differently, although it is unclear which direction this would bias the estimates.

Second, the simulations assume that the strategic releases are unexpected, both in an econometric sense (as deviations from the statistical expectation of the model) and from the perspective of market participants ${ }^{30}$ If strategic releases are expected, then their effects will be incorporated into existing oil prices and spreads. While this suggests imperfections in the timing of the effects found in the simulation, it does not undermine their existence. Indeed, as Devarajan and Hubbard (1982) point out, expectations of future releases help calm markets before they actually occur - so long as policymakers eventually follow through on that expectation. This relates to another issue in the vein of the Lucas critique. If the government commits to a policy of releasing inventories when supply disruptions induce steep backwardation, markets will anticipate this policy, stabilizing oil markets before any particular release is announced. While this expectations channel has desirable anticipatory and stabilizing effects, it also could undermine the value of the price spread itself as an indicator of the severity of supply disruptions.

A third caveat is that the estimated VAR underlying the simulations represents the "average" relationships between the variables over the sample period. The relationships during times of extreme disruption may differ from these average relationships. However, the substantial variation in the series during these extreme events provides a non-trivial portion of the variation identifying our VAR estimates, partially allaying this concern.

Finally, our model does not directly treat refined product markets. This is mainly a concern in emergency scenarios where refined markets are disproportionately important, such as during Hurricane Katrina, which severely damaged refining operations. Future work could apply these techniques to more directly explore refined product market disruptions, with relevance to the consideration of the value of refined product reserves.

\footnotetext{
${ }^{30}$ As pointed out by $\overline{\text { Kilian and Murphy } \sqrt{2014} \text {, }}$ with forward-looking investors, these two types of expectations can differ, although VAR models often implicitly equate them.
} 


\section{Conclusion}

Understanding the dynamic relationships between oil spot prices, price spreads, and inventories is key for both market participants and policymakers considering releases from strategic oil reserves, such as the SPR. First, we make the conceptual point that spreads convey market-based information about expectations regarding the severity and persistence of supply disruptions, with clear implications for when SPR releases are advisable. Namely, steep backwardation suggests disruptions are serious, unlikely to be quickly moderated by private market forces, and expected to be transitory, indicating a stronger case for releasing reserves. The spread thus provides an indicator guiding policymakers whether to release reserves, or to hold them in case a disruption might deteriorate further.

We use a VAR to estimate the dynamic relationship between oil spot prices, price spreads, and commercial inventories. This relationship illustrates the magnitude of the impacts of SPR releases, with implications for how many barrels to release in times of supply disruption. The estimates suggest that SPR releases-modeled as surprise inventory shocks - can have substantial effects on oil prices and spreads. Impulse response functions suggest that stock releases can temporarily reduce spot prices by about $2 \%$ to $3 \%$ and mitigate backwardation by approximately 0.8 percentage point for each $1 \%$ addition to commercial inventories (approximately equal to 10 million barrels). Simulations suggest that past releases may have mitigated increases in oil prices on the order of $15 \%$ to $20 \%$ and prevented approximately 5 percentage points of backwardation in crude oil futures. These estimates can guide policymakers in determining how many barrels to release from the SPR in times of supply disruption to achieve specified market impacts.

\section{References}

Baumeister, C., And L. Kilian (2016a): "Forty Years of Oil Price Fluctuations: Why the Price of Oil May Still Surprise Us," The Journal of Economic Perspectives, 30(1), 139-160.

(2016b): "A General Approach to Recovering Market Expectations from Futures Prices with an Application to Crude Oil," manuscript.

Brennan, M. J. (1958): "The Supply of Storage," The American Economic Review, pp. 50-72.

Chao, H.-P., and A. S. Manne (1983): "Oil Stockpiles and Import Reductions: A Dynamic Programming Approach," Operations Research, 31(4), 632-651. 
Devarajan, S., and R. G. Hubbard (1982): "Drawing down the Strategic Petroleum Reserve: The Case for Selling Futures Contracts," in Stockpile Policy, chap. 11, pp. 187-196. Harvard University, Cambridge, MA.

Fama, E. F., And K. R. French (1987): "Commodity Futures Prices: Some Evidence on Forecast Power, Premiums, and the Theory of Storage," Journal of Business, pp. 55-73.

- (1988): "Business Cycles and the Behavior of Metals Prices," The Journal of Finance, 43(5), 1075-1093.

Hamilton, J. D. (2009): "Understanding Crude Oil Prices," Energy Journal, 30(2), 179-206.

Hamilton, J. D., And A. M. Herrera (2004): "Oil Shocks and Aggregate Macroeconomic Behavior: The Role of Monetary Policy: A Comment," Journal of Money, Credit, and Banking, 36(2), 265-286.

Hubbard, R. G., and R. J. Weiner (1983): “The 'sub-trigger' crisis: An economic analysis of flexible stock policies," Energy Economics, 5(3), 178-189.

(1985): "Managing the Strategic Petroleum Reserve: Energy Policy in a Market Setting," Annual Review of Energy, 10(1), 515-556.

(1986): "Inventory Optimization in the U.S. Petroleum Industry: Empirical Analysis and Implications for Energy Emergency Policy," Management science, 32(7), 773-790.

Kilian, L. (2008): "The Economic Effects of Energy Price Shocks," Journal of Economic Literature, 46(4), 871-909.

(2009): "Not All Oil Price Shocks Are Alike: Disentangling Demand and Supply Shocks in the Crude Oil Market," American Economic Review, 99(3), 1053-69.

_ (2016): "The Impact of the Shale Oil Revolution on U.S. Oil and Gasoline Prices," Review of Environmental Economics and Policy, 10(2), 185-205.

(2017a): "How the Tight Oil Boom Has Changed Oil and Gasoline Markets," Papeles de Energia, 3, $79-102$.

(2017b): "The Impact of the Fracking Boom on Arab Oil Producers," Energy Journal, 38(6), $137-160$. 
Kilian, L., And T. K. LeE (2014): "Quantifying the speculative component in the real price of oil: The role of global oil inventories," Journal of International Money and Finance, 42, 71-87.

Kilian, L., AND H. LütKePOHL (2017): Structural vector autoregressive analysis. Cambridge University Press, forthcoming.

Kilian, L., And D. P. Murphy (2014): "The Role of Inventories and Speculative Trading in the Global Market for Crude Oil," Journal of Applied Econometrics, 29(3), 454-478.

Pindyck, R. S. (2001): "The Dynamics of Commodity Spot and Futures Markets: A Primer," The Energy Journal, pp. 1-29.

Scheitrum, D. P., C. A. Carter, and A. M. Jaffe (2015): "Testing substitution between private and public storage in the U.S. oil market: A study on the U.S. Strategic Petroleum Reserve," Energy Economics. Stevens, R. (2014): "The Strategic Petroleum Reserve and Crude Oil Prices," .

Teisberg, T. J. (1981): “A Dynamic Programming Model of the U.S. Strategic Petroleum Reserve," The Bell Journal of Economics, pp. 526-546.

Working, H. (1949): "The Theory of Price of Storage," The American Economic Review, 39(6), 1254-1262. 


\section{A Appendix}

\section{A.1 All Impulse Response Functions}

In the body, we focused on a selected set of impulse response functions of interest (those relating the inventories and spreads). All impulse response functions are shown in Figure A.1. When the responses are statistically significant, their direction and size generally comport with economic theory and intuition. One interesting response of note is the effect of a shock to OPEC production on crude oil prices (seen in row 4, column 3), which suggests $1 \%$ to $2 \%$ price reductions, albeit with large standard errors. Interestingly, this response does not primarily represent a direct effect of production on prices. Instead, it derives from an indirect effect of production shocks on inventory builds (shown in row 2, column 3), which in turn reduces prices. This can be seen in the IRF by observing that prices do not decline very much immediately after an OPEC production shock, only beginning to decline after inventories have been building for approximately 8 months ${ }^{31}$

\section{A.2 Estimation using Baumeister-Kilian Data}

As discussed in section 3.2 we also estimate our model using the expected future (12-month) spot price series from Baumeister and Kilian (2016b) generously provided by those authors. As described in section 3.1.1, we use a combined time series of WTI (before 2010) and Brent (2010+). We use an analogous series generated by combining Baumeister-Kilian's expected price series for both WTI and Brent. This series is plotted, along with futures prices, in Figure A.2

We re-estimated our VAR using the spread between the Baumeister-Kilian (BK) 12-month expected spot price and the prompt-month future price (i.e., the (log) blue line minus the (log) black line). By contrast, our main specification uses the difference between the actual 12-month future and the prompt month price (the $(\log )$ red line minus the (log) black line). Due to data limitations, the sample period here is February 1990 to December 2015, slightly shorter than the period of December 1988 to June 2016 in our main specification.

Figures A.3 and A.4 show the IRFs using this alternative spread series. These IRFs strongly resemble the corresponding ones in our primary specification, shown in Figures 2 and A.1. Focusing on the IRFs of interest - the effect of an inventory shock shown in Figure A.3 the effect of the BK series is minor. The only substantial difference is that the spread response is somewhat larger when it is computed using the BK series (see last panel, about $1.5 \%$ versus $0.8 \%$, although the confidence intervals overlap). This difference is

\footnotetext{
${ }^{31}$ This result also appears if we use world crude production in place of OPEC-only production in the VAR.
} 

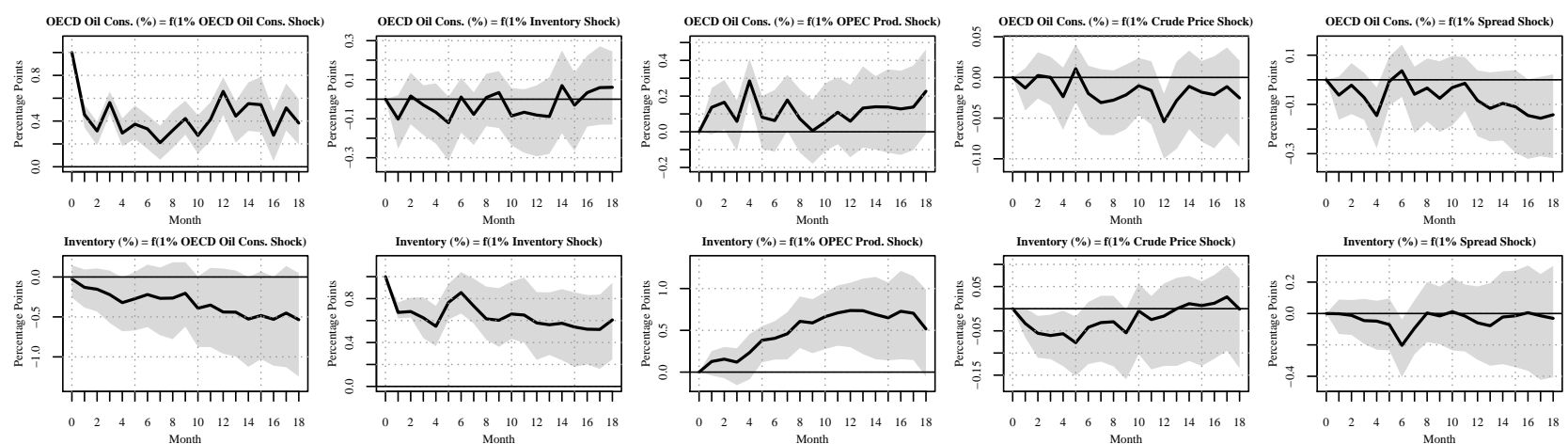

OPEC Prod. (\%) = f(1\% OECD Oil Cons. Shock
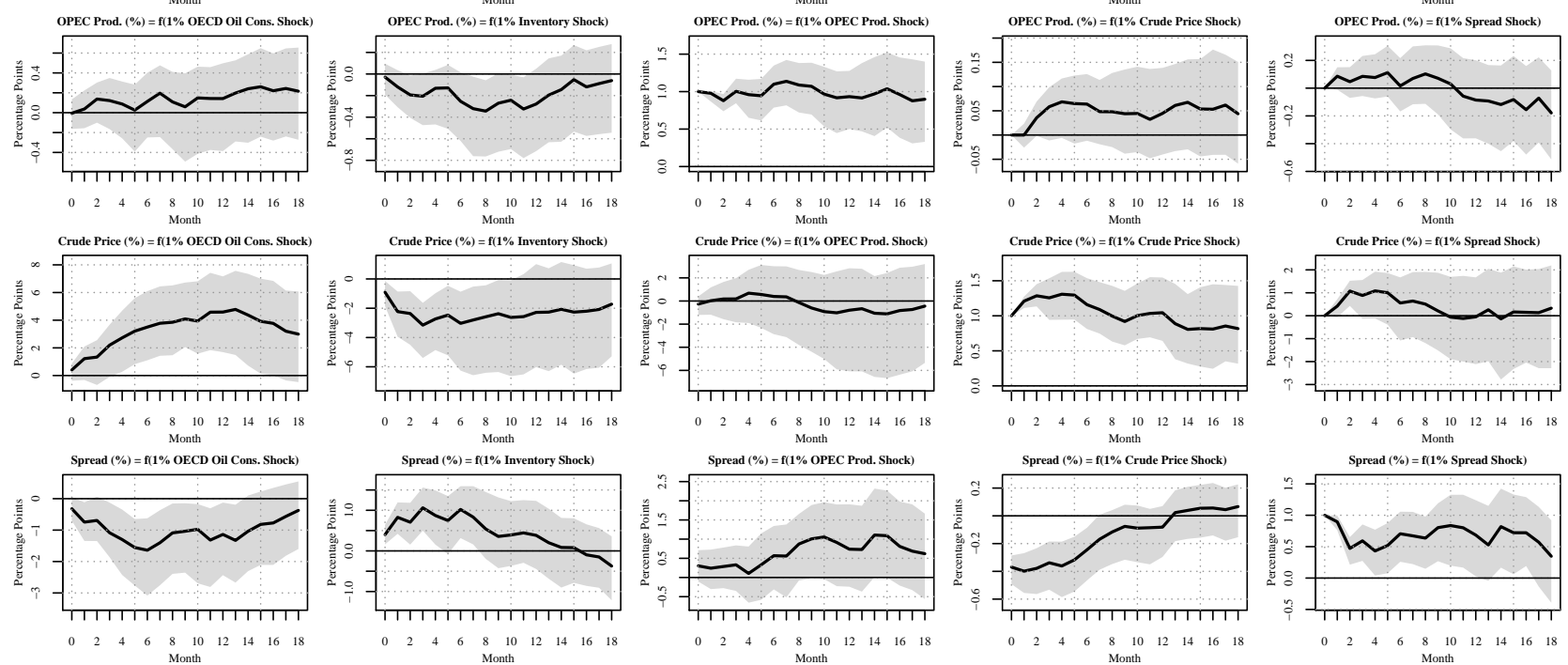

Figure A.1: All Impulse Response Functions

Notes: All shocks are 1 percentage point in magnitude. Columns represent impulse variables, rows represent response variables. For example, the $2^{\text {nd }}$ column shows the response of all variables to an impulse to inventories, corresponding to the graphs shown in Figure 2 And the $4^{\text {th }}$ row represents how prompt-month oil prices respond to shocks to each of the five variables. Shaded areas represent $95 \%$ confidence intervals computed through 100 bootstrap iterations.

modest, which suggests that inventory shocks do not substantially affect the risk premium, since that is the only difference between the two series.

Most of the other IRFs (shown in Figure A.4) are also qualitatively unchanged. The exception is the final column of that figure, showing the effects of a spread shock on the other variables. It is unsurprising that these IRFs show the largest difference because this spread shock represents a different economic concept. Namely, it excludes shocks to the risk premium. However, the standard errors under each method generally overlap both zero and each other. 


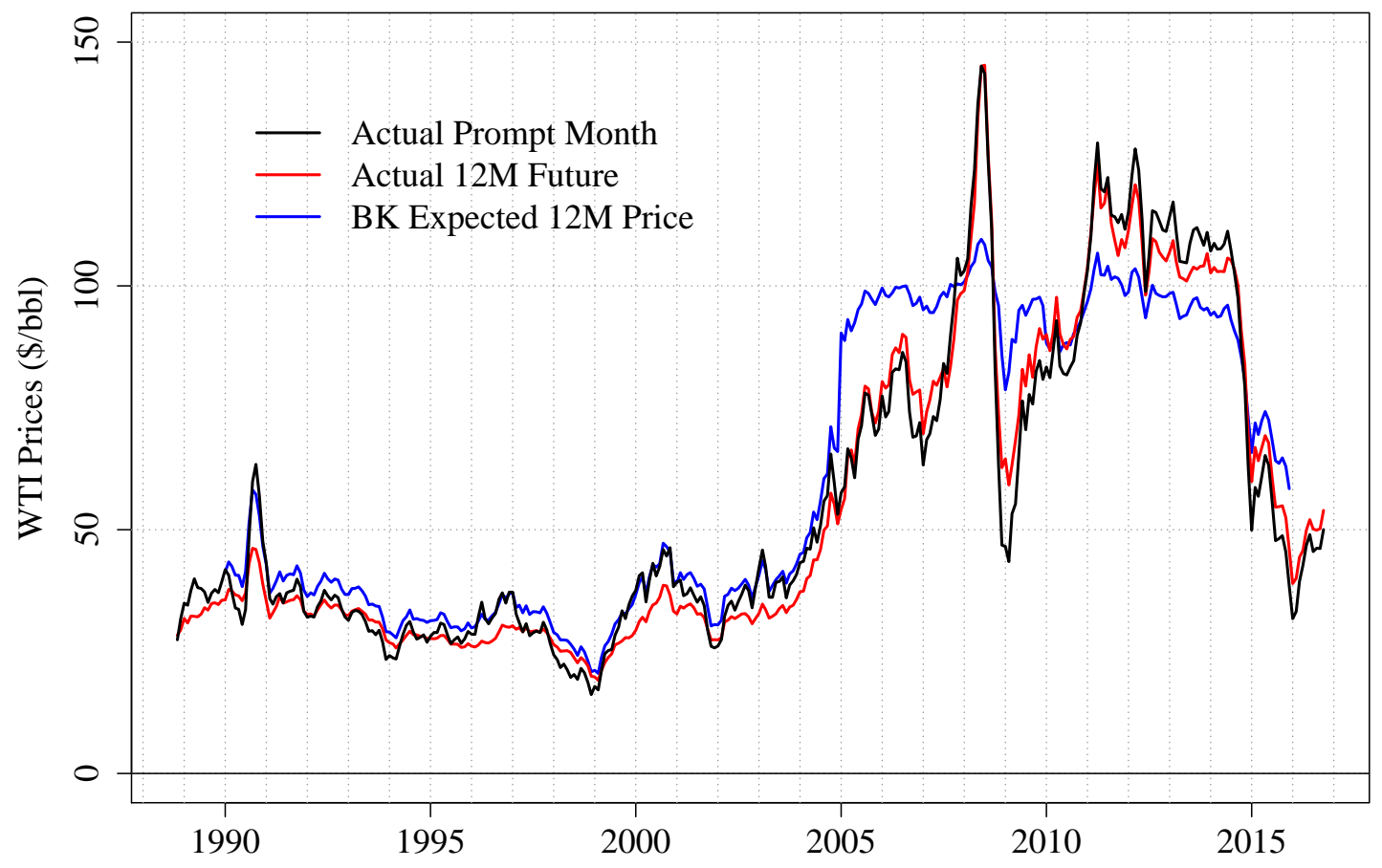

Figure A.2: Crude Oil Futures Prices and Baumeister-Kilian (BK) Expected Spot Prices
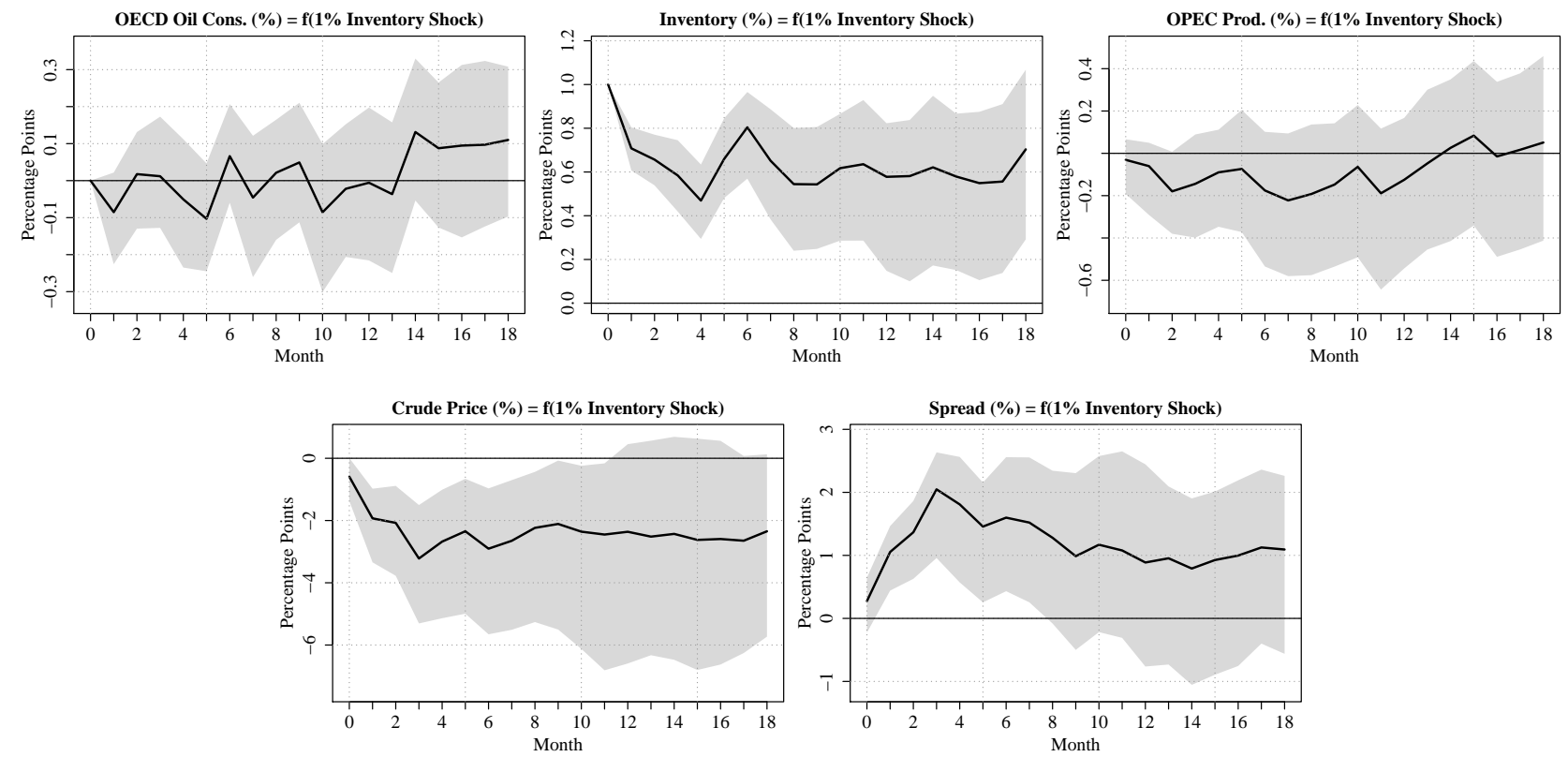

Figure A.3: Cumulative Impulse Responses from a 1 Percentage Point Shock to Inventories, using BK Data Notes: Compare to IRFs in Figure 2 Shaded areas represent 95\% confidence intervals computed through 100 bootstrap iterations. 

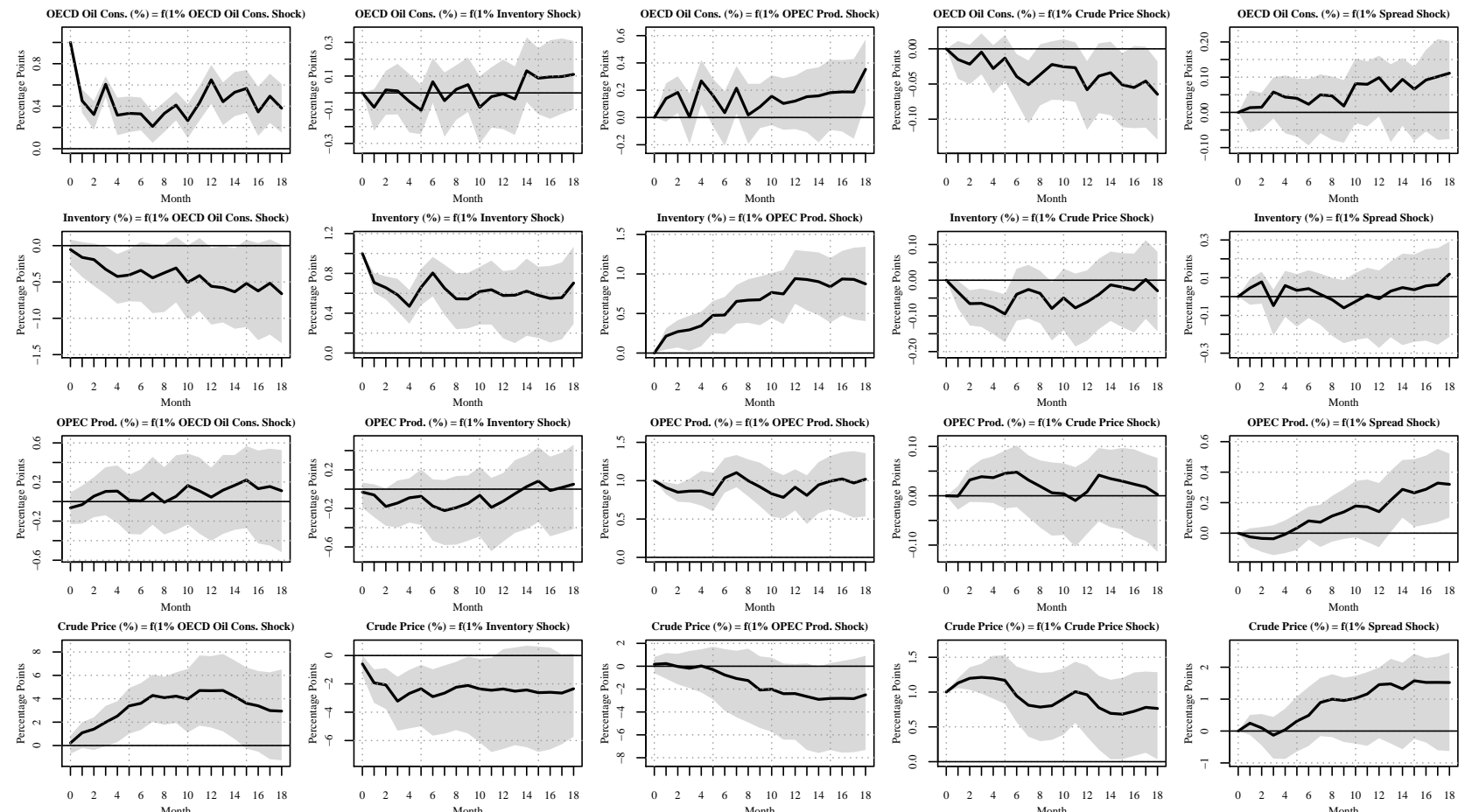

\begin{tabular}{lllllllllll}
0 & 2 & 4 & 6 & 8 & 10 & 12 & 14 & 16 & 1 \\
\hline & & & & Month & & & &
\end{tabular}

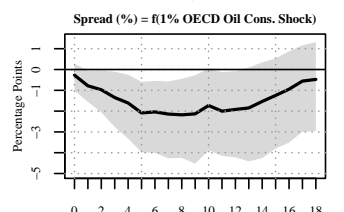

Spread $(\%)=f(1 \%$ Inventory Shock
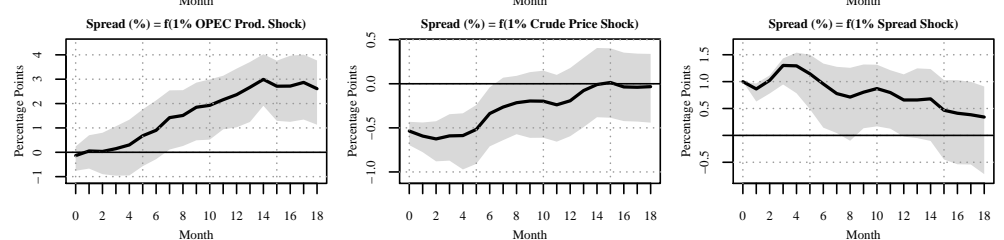

Figure A.4: All Impulse Response Functions, using BK Data

Notes: Compare to IRFs in Figure A.1 All shocks are 1 percentage point in magnitude. Columns represent impulse variables, rows represent response variables. For example, the $2^{\text {nd }}$ column shows the response of all variables to an impulse to inventories, corresponding to the graphs shown in Figure 2. And the $4^{\text {th }}$ row represents how prompt-month oil prices respond to shocks to each of the five variables. Shaded areas represent $95 \%$ confidence intervals computed through 100 bootstrap iterations. 